\title{
A educação superior no Brasil na perspectiva do direito social: cenários que levam ao programa Prouni*
}

\author{
The higher education in Brazil in the perspective of social law: \\ scenarios that take the program Prouni
}

\section{Educación superior en Brasil desde la perspectiva del derecho social: escenarios que llevan al programa Prouni}

\author{
LARISSA RAMALHO PEREIRA** \\ FRANCISCO ARSELI KERN***
}

\begin{abstract}
$\longrightarrow \gg \longrightarrow$
RESUMO

O presente artigo aborda a educação superior no Brasil, sob as diferentes perspectivas e posições oriundas da relação indissociável entre educação e direito social, tendo em vista que o eixo analítico deste trabalho encontra-se pautado na garantia universal do direito à educação. Nesse sentido, o mesmo apresenta um breve resgate histórico sobre a educação no Brasil, dando ênfase à construção histórica, social, econômica e política da educação brasileira, destacando os aspectos dos cenários educacionais de cada período, até chegar ao Programa Universidade para Todos - Prouni, evidenciando sua natureza e os diferentes olhares e análises sobre o mesmo.
\end{abstract}

Palavras-chave: Política de educação. Educação superior. Prouni.

\begin{abstract}
This article discusses higher education in Brazil, under the different perspectives and positions from the inseparable relationship between education and social right, considering that the analytical axis of this work is based on the universal guarantee of the right to education. In this sense, the same provides a brief historical rescue on education in Brazil, emphasizing the historical, social, economic construction and education policy, highlighting aspects of educational scenarios of character each time, until you reach the University for All Program - Prouni, the nature of this program and the different perspectives and analyses on the same.
\end{abstract}

Keywords: Education policy. Higher education. Prouni.

\section{RESUMEN}

Este artículo aborda la educación superior en Brasil, bajo diferentes perspectivas y posiciones de la inseparable relación entre la educación y el derecho social, teniendo en cuenta que el eje analítico de este trabajo se basa en la garantía universal del derecho a la educación. En este sentido, el mismo ofrece un rescate histórico breve sobre la educación en Brasil, destacando la histórica, social y económica construcción y educación política, destacando los aspectos de los escenarios educativos de carácter cada vez, hasta llegar a la Universidad para el Programa de Todos - Prouni, la naturaleza de este programa y las diferentes perspectivas y análisis sobre el mismo.

Palabras clave: Educación. Política educativa. Prouni.

* Este artigo é resultado de pesquisa desenvolvida com universidades privadas da Grande Porto Alegre/RS sobre as políticas de assistência estudantil no âmbito da rede privado/filantrópica que visam ao acesso e à permanência do aluno prounista à universidade. A pesquisa faz parte da dissertação de mestrado intitulada "O acesso e permanência do aluno prounista na universidade privado-filantrópica", defendida em 2014, no Programa de Pós-Graduação em Serviço Social da PUCRS.

** Assistente Social. Mestre em Serviço Social pela Pontifícia Universidade Católica do Rio Grande do Sul - PUC/RS (2014). Professora Titular do Curso de Serviço Social do Centro Universitário Franciscano (UNIFRA). E-mail: <larissa.ramalho.pereira@gmail.com>.

*** Assistente Social. Mestre e Doutor em Serviço Social pela Pontifícia Universidade Católica do Rio Grande do Sul. Professor do Curso de Serviço Social da Escola de Humanidades da Pontifícia e Professor colaborador do Programa de Pós-Graduação Serviço Social da mesma Universidade. Coordenador do Curso de Graduação em Serviço Social e Coordenador do Grupo de Pesquisas Redes, Identidades e Subjetividade, vinculados a Escola de Humanidades da PUCRS.E-mail: <francisco.kern@pucrs.br>. 


\section{INTRODUÇÃO}

A história da educação no Brasil, ao contrário do que se possa pensar, inicia-se com a chegada dos jesuítas. Estes, por sua vez, tiveram grande influência no sistema educacional brasileiro, que avançou no decorrer dos anos. Segundo Freitag (1980, p. 46), em seu livro Escola, estado e sociedade, caracterizando-se em os marcos históricos da educação no Brasil, tem-se como ponto de partida três momentos-chave na história, ligados a modelos da economia brasileira de cada período, como segue:

a) 1ํo período: de 1500 a 1930, abrangendo a Colônia, o Império e a Primeira República;

b) $2^{\circ}$ período: de 1930 a 1960, da Revolução de 30 à redemocratização;

c) $3^{\circ}$ período: de 1960 , a ditadura militar e outros fatos históricos.

Ao lançar o olhar para a história, observa-se que após a ditadura militar muito tempo se passou. E esse é mais um momento-chave na história da educação brasileira que deve ser incluído, intitulado como:

d) 4o período: de 1988 a 2013, a emergência de uma esfera pública não estatal: da Constituição de 1988 ao surgimento do Prouni.

A partir dos três primeiros períodos históricos, é possível compreender a afirmativa que se registra neste artigo e que traz a forte influência dos padres jesuítas na educação do Brasil. De acordo com Freitag (1986, p. 47), "a fase colonial caracterizava-se pela inexistência de instituições autônomas que compusessem a sociedade política. Essa se reduzia às representações locais do poder da metrópole".

Através das escolas jesuíticas, reproduziam-se as relações de dominação e as ideologias dominantes. Isso porque, na medida em que os jesuítas preparavam os futuros bacharéis em Belas-Artes, Direito e Medicina, tanto na Colônia como na Metrópole, abasteciam os quadros de administradores locais. Logo, asseguravam a reprodução social dominante da época. Nesse sentido, ainda formavam teólogos para garantir a continuidade da cultura religiosa, ou seja, seus sucessores ou "quadros" hierárquicos. A educação era utilizada pela Igreja Católica como uma "arma pacífica" para manutenção da hegemonia dominante.

\section{POLÍTICA DE EDUCAÇÃo SUPERIOR NO BRASIL: UM BREVE RESGATE HISTÓRICO}

O período da colonização é marcado pela exploração do Brasil, já que os portugueses vinham em busca das riquezas e fortunas que se apresentavam majestosas. No entanto, os portugueses, ao não se preocuparem com a estrutura econômica, política e educacional da população do país, tornaram-se suscetíveis a inúmeros problemas, dentre eles a escassez da matéria-prima e o mau trato para com a mesma, levando-os à decadência. Esta esteve pautada por inúmeros problemas, dentre eles métodos rudimentares de extração de ouro e diamante, e cultivo da agricultura inadequado, em função da falta de habilidades e conhecimentos técnicos para manuseio da terra, entre outros fatores. Freitag (1986, p. 48) assinala:

Apesar da expulsão transitória dos jesuítas do Brasil no fim do século XVIII, a Igreja preservou sua força na sociedade civil ainda em fases do Império e da I República. É ela que, basicamente, continuava a controlar as instituições de ensino, encarregando-se ainda por muito tempo da função de reprodução da ideologia.

Nas fases do Império e da I República, a base da economia brasileira permanecia a mesma: agroexportação, passando do açúcar para o café. Nesse período, a força de trabalho escravocrata começa a ser substituída por imigrantes, movimento que é mais fortalecido no fim do Império, quando o regime de trabalho passa a ser livre, por meio da Lei Áurea ${ }^{1}$. Contudo, a lógica permanecia a mesma, conforme ressalta Freitag (1986, p. 48): "Não há necessidade de qualificação da força de trabalho imigrante pela escola brasileira, pois ela já vem qualificada para o tipo de tarefas que a esperam".

A riqueza social se reflete no desenvolvimento da natureza humana condicionada ao desenvolvimento das forças produtivas. Marx, por isso, integra os conceitos de educação e de formação profissional, os quais, na pedagogia idealista alemã, sempre estiveram separados; critica a divisão social do trabalho, que subjuga o homem à máquina, e lança as bases de uma teoria da personalidade que supere a especialização. As faculdades do homem devem ser desenvolvidas em todos os domínios da vida social, isto é, no trabalho, na economia, na cultura, no consumo, etc.

Com a transferência da corte portuguesa para o Brasil, em 1808, surge a necessidade de novos quadros técnicos e administrativos. Assim, é urgente fortalecer a sociedade política, justificando a criação de escolas militares, de nível superior, na abrangência do território nacional. Com D. João VI, a política educacional brasileira é alterada. Surgem os primeiros cursos superiores de Direito, Medicina, Engenharia, porém não universidades.

\footnotetext{
${ }^{1}$ A Lei Áurea (Lei Imperial no 3.353), sancionada em 13 de maio de 1888, extinguiu a escravidão no Brasil; foi precedida pela Lei no 2.040 (Lei do Ventre Livre), de 28 de setembro de 1871, que libertou todas as crianças nascidas de pais escravos, e pela Lei no 3.270 (Lei Saraiva-Cotegipe), de 28 de setembro de 1885 , que regulava "a extinção gradual do elemento servil”.
} 
A Igreja Católica continuava a desempenhar paralelamente sua função de reprodução ideológica, por meio das escolas de natureza confessional. Com o fim do Império e o começo da República, vislumbra-se uma política educacional de cunho estatal, oriunda do fortalecimento do Estado enquanto sociedade política. Freitag (1986, p. 49) refere que "até então a política educacional era feita quase que exclusivamente no âmbito da sociedade civil, por uma instituição todo-poderosa, a Igreja".

No final da década de 1920, com a crise do café, produto condutor da economia brasileira, o Estado foi forçado a comprar a produção excedente, com auxílio de créditos adquiridos no exterior, com vistas a fortalecer e valorizar a economia nacional. Isso porque, em âmbito mundial, um dos maiores países consumidores do café brasileiro, os Estados Unidos da América, entrava em crise no ano de 1929. Essa crise é conhecida como a "Grande Depressão" ou, por vezes, como a "Crise de 29", que causou um período de grande recessão econômica, instaurando drásticos problemas sociais como o desemprego.

Diante desse novo panorama socioeconômico, o foco, que era na agricultura, sofre mudanças. As forças agora são concentradas na produção industrial, diversificando a economia e abrindo espaço para a indústria. Surge uma nova classe social denominada burguesa-industrial. Conforme ressalta Freitag (1986, p. 50), "a classe até então hegemônica dos latifundiários cafeicultores é forçada a dividir o poder com a nova classe burguesa emergente". $\mathrm{O}$ autor segue afirmando:

Em consequência dessa nova situação, há uma reorganização dos aparelhos repressivos do Estado. Com auxílio de certos grupos militares (tenentes) e apoiados pela classe burguesa, Vargas assume o poder em 1930, implantando, em 1937, o Estado Novo, com traços ditatoriais. Isto significa que a sociedade política invade áreas da sociedade civil, subordinando-as ao seu controle. É o que ocorrera com as instituições de ensino. Percebe-se uma intensa atividade do Estado em ambas as instâncias da superestrutura. É criado, pela primeira vez, em 1930, um Ministério de Educação e Saúde, ponto de partida, segundo Valnir Chagas, para mudanças substanciais na educação, entre outras, a estruturação de uma universidade. De fato, só então são fundadas no Brasil as primeiras universidades, pela fusão de uma série de instituições isoladas de ensino superior (FREITAG, 1986, p. 50).

Mudanças marcantes contribuíram para a fundação das universidades brasileiras, significando a introdução de um novo sistema de educação superior, balizado pela promulgação dos Estatutos das Universidades Brasileiras (Decreto no 19.851, de 14 de abril de 1931). Porém, somente em 1934, foi criada a primeira instituição de nível superior no Brasil, a Universidade de São Paulo.
A inexistência de uma universidade, apesar do funcionamento do ensino superior desde o início do século XIX, colocava o Brasil numa situação de inferioridade em relação aos outros países sul-americanos. A intelectualidade brasileira não se conformava com o fato do Brasil e o Paraguai serem os únicos países da América do Sul que ainda não contavam com uma universidade, sendo que países como México e o Peru, por exemplo, já no século XVI, haviam organizado tal instituição de ensino superior. A situação do Brasil, por isso mesmo, era considerada humilhante (PILETTI, 2000, p. 80).

O golpe de Estado de 1937 possibilitou a Getúlio Vargas amplos poderes para remanejar a estrutura do Estado, assim "a política liberal do Governo é substituída por um dirigismo estatal, que favoreceu a indústria" (ROMANELLI, 1999, p. 50). O golpe é determinante para os novos rumos do Brasil em uma conjuntura crítica. Somente em 1945, o período ditatorial rompe-se e, então, é derrotada a ditadura Vargas, conforme observa Freitag:

A fase que vai de 45 até o início dos anos 60 corresponde à aceleração e diversificação do processo de substituição de importações. Ao nível político, sua expressão mais perfeita é o Estado populistadesenvolvimentista, que representa uma aliança mais ou menos instável entre um empresariado nacional, desejoso de aprofundar o processo de industrialização capitalista, sob o amparo de barreiras protecionistas, e setores populares, cujas aspirações de participação econômica (maior acesso a bens de consumo) e política (maior acesso aos mecanismos de decisão) são manipuladas tacitamente pelos primeiros, a fim de granjear seu apoio contra as antigas oligarquias (FREITAG, 1980, p. 55).

Com o restabelecimento das forças democráticas brasileiras e reorganização da economia no contexto internacional, as funções até então atribuídas à escola tiveram de serem revistas. A Constituição de 1946 estabelece novas regras, dentre elas a necessidade da elaboração de novas leis e diretrizes para o ensino no Brasil. Nesse contexto, Piletti relata:

Apesar da mudança de regime e da nova Constituição, a legislação educacional herdada do Estado Novo vigorou até 1961, quando teve início a vigência da Lei de Diretrizes e Bases da Educação Nacional. Esse fato, contudo, não impediu que numerosas campanhas fossem organizadas, visando à ampliação e à melhoria do atendimento escolar, refletido na expansão do número de matrículas (PILETTI, 2000, p. 99).

Inúmeros embates políticos travados na época para a aprovação da LDB se estenderam até sua promulgação, pois se buscava um equilíbrio, um consenso entre a 
classe burguesa nacional e os interesses das frações de classe mais tradicionais, bem como entre setor público e privado. Quando entra em vigor, pode-se dizer que já estava ultrapassada.

De acordo com Freitag (1980, p. 59), "em dezembro de 1961 já se delineiam claramente as novas tendências da internacionalização do mercado interno". Em decorrência desse movimento, possíveis mudanças políticas, econômicas e sociais são apontadas, implicando diretamente a política educacional então vigente.

Cabe ressaltar dois artigos da Lei no 4.024/61, mantida pela reforma de 1971, que preconizam: "O ensino superior tem por objetivo a pesquisa, o desenvolvimento das ciências, letras e artes, e a formação de profissionais de nível universitário "(Art. 66); e, "o ensino superior será ministrado em estabelecimentos agrupados ou não em universidades, com a cooperação de institutos de pesquisa e centros de treinamento profissional" (Art. 67).

Nas décadas de 1950 e 1970 são criadas universidades federais em todo o território nacional, pelo menos uma em cada estado, além de universidades estaduais, municipais e particulares. Esse caráter descentralizado da educação superior segue o movimento da Lei de Diretrizes e Bases da Educação Nacional de 1961.

A expansão do ensino médio, conforme previa a LDB, e a necessidade de mão de obra qualificada para trabalhar nas indústrias impulsionaram a criação de novas universidades e a "federalização" de faculdades estaduais e privadas, entre outros fatores. Contudo, esse aumento expressivo de universidades, da ampliação da educação superior, sem adequado planejamento, resulta na "insuficiência de fiscalização por parte do poder público, uma queda da qualidade de ensino e a imagem 'mercantilista' e negativa da iniciativa privada" (FIGUEIREDO, 2005, p. 73).

O processo conflituoso de aprovação da LDB desencadeou alguns movimentos populares a seu favor, e faz-se relevante registrar: Campanha em Defesa da Escola Pública", encampada principalmente pela UNE (União Nacional dos Estudantes); Centros Populares de Cultura da UNE; Movimento de Educação de Base da CNBB; Método de Alfabetização de 40 horas de Paulo Freire, entre outras iniciativas.

No período da ditadura militar, a educação passa por duas grandes reformas nos anos de 1968 e 1971. Estas foram precedidas pelos acordos MEC - Usaid (Ministério da Educação e Cultura e United States Agency for International Development), nos quais o Brasil receberia apoio técnico e financeiro para programar as reformas.

Figueiredo (2005) entende que o golpe militar fez com que os movimentos estudantis como o da UNE fossem extintos, evitando a organização nacional dos estudantes e permitindo, de forma velada, a atuação dos Diretórios Acadêmicos (DAs) e dos Diretórios Centrais dos Estudantes (DCEs), somente no âmbito dos cursos e das universidades. Dessa maneira, ações políticas - ditas subversivas - poderiam ser contidas, e seria mais seguro manter-se no poder controlando a juventude brasileira.

No decorrer da década de 1960 e 1970, foram verificadas mudanças significativas no ensino superior do Brasil, as quais mantiveram características de caráter excludente. Nesse sentido, Lima aponta:

A identificação da educação como um serviço público não estatal foi operacionalizada como uma crescente desresponsabilização do Estado com a educação superior, por meio da redução de verbas públicas para seu financiamento e, simultaneamente, do estímulo ao empresariamento deste nível de ensino, sob a aparência de democratização do acesso à educação (LIMA, 2007, p. 126).

Nesse período, registra-se também um crescente aumento de privatizações do ensino, em que o poder público destina verbas para a iniciativa privada ofertar tais serviços. Nas décadas posteriores, o movimento de privatização se acelera e cresce, conforme relata Figueiredo:

Nunca na história do país foram abertas tantas universidades particulares como nos anos 80 e 90 [...]. No Brasil, na década de noventa, a reforma educacional, através da Lei de Diretrizes e Bases (LDB) para educação nacional e do Plano Nacional de Educação (PNE), apresentou-se numa perspectiva de dar forma às políticas neoliberais, caracterizadas principalmente pela privatização, entendendo esta como a entrada desenfreada de recursos não públicos para manter as atividades próprias da universidade (FIGUEIREDO, 2005, p. 75).

Cabe ressaltar importantes acontecimentos ocorridos nos anos 1980 e 1990 para a educação brasileira: a Constituição da República Federativa do Brasil, de 1988, e a Lei no 9.394/96, a nova LDB, que compreendera novamente todos os graus e modalidades de ensino em uma única legislação. Para elucidar os marcos históricos acima mencionados, cita-se Piletti, quando o mesmo refere:

Proposto pelo deputado Octávio Elísio, ainda em novembro de 1988, o novo projeto de lei de diretrizes e bases da educação nacional teve uma tramitação tumultuada de oito anos no Congresso Nacional. Aprovado com substanciais modificações na Câmara foi enviado ao Senado em maio de 1993. No Senado, foi substituído por um novo projeto de autoria do senador Darcy Ribeiro. Voltou depois à Câmara, onde foi aprovado com poucas alterações. Foi finalmente sancionado pelo Presidente da República no dia 20 de dezembro de 1996, data do $35^{\circ}$ aniversário da primeira LDB, como lei 9.394/96 (PILETTI, 2000, p. 143). 
Até o período atual, já se passam cerca de 40 anos do primeiro período da contrarreforma universitária, marcada pela transição das décadas de 1970 a 1990, as quais compreenderam substanciais mudanças nos modelos e concepções de universidades, antes instituição social, ora instituição empresarial. Cabe ainda ressaltar, nessa primeira fase da contrarreforma universitária, que o Brasil era governado pelo presidente Fernando Collor de Mello (1990-1992), depois sucedido pelo governo de Itamar Franco (1993-1994), os quais propunham ações para a educação, com base nas "noções de equidade, eficiência e competitividade na educação" (LIMA, 2007, p. 132).

No âmbito mundial, destaque para as discussões travadas acerca da educação no início dos anos 1990: a Conferência Mundial de Educação para Todos, organizada pela Unesco, pelo Fundo das Nações para o Desenvolvimento (Pnud) e pelo Banco Mundial, em Jomtien, Tailândia. O tema central das discussões foi balizado pelo lema "Educação para Todos", que, segundo Lima (2007), articulava-se à conjuntura política e econômica que marcou o início da década de 1990. A autora identifica os eixos analíticos norteadores das discussões na referida conferência:

Os organismos internacionais do capital necessitam desenvolver políticas de alívio das tensões sociais causadas pela crise do endividamento dos países periféricos e pela execução dos ajustes estruturais impostos ao longo da década (perdida) de 1980; b) as políticas focalizadas no alívio da pobreza estarão articuladas com a necessidade de governabilidade, ou seja, da conjugação de segurança e estabilidade econômica para pagamento das dívidas; c) a necessidade de ampliação de áreas de lucratividade para investidores internacionais (LIMA, 2007, p. 56).

Ainda durante o evento, a Unesco e o Banco Mundial (BM) discutiram alguns entendimentos sobre os conceitos de educação básica, uma vez que a primeira entendia que a educação básica contemplaria o ensino fundamental e médio, já o BM seria restrito ao ensino fundamental. Porém, ambos partilhavam de pontos em comum para tratar tal assunto:

- O acesso à educação básica estaria circunscrito às necessidades básicas de aprendizagem como vias de integração dos povos na sociedade da informação;

- O acesso à educação básica seria identificado como igualdade de oportunidades, marcado pela concepção de educação como formadora de valores e comportamentos;

- O estímulo à diversificação das fontes de financiamento da educação seria considerado o elemento central na reformulação educacional em curso; e
- O acesso à educação deveria considerar a utilização das TIC, identificadas como tecnologias educativas, como estratégia de aprendizagem ao longo da vida (UNESCO, BANCO MUNDIAL, 1990).

Rebatimentos das diretrizes e concepções desses organismos internacionais são vivenciados no Brasil e no mundo, uma vez que o projeto neoliberal de mundialização da educação/sociabilidade constitui novos campos de exploração para o capital. Diante desse cenário, a década de 1990 foi marcada pela massificação da educação superior, com ênfase para o governo de Fernando Henrique Cardoso (FHC), quando houve um grande incentivo à explosão de vagas nas universidades privadas. A expansão provocou outro problema para essas instituições: o alto número de inadimplência e evasão dos alunos levou as empresas de ensino superior privado a chegar a uma situação financeira crítica no início dos anos 2000. No tocante às universidades públicas, essas vivenciaram intenso sucateamento (precariedade dos recursos humanos e estruturais) diante dos investimentos e incentivos fiscais nas instituições privadas, como também ausência de uma política efetiva de assistência estudantil, culminando na segunda fase da contrarreforma universitária.

Boschetti ressalva que houve mudanças para a educação superior, seguradas pela LDB, contudo foi a partir dos governos de FHC e Lula que as mesmas foram implementadas e operacionalizadas:

Todas as medidas ali previstas - exame nacional de cursos, mestrados profissionalizantes, substituições dos currículos mínimos por diretrizes curriculares, cursos sequenciais, ensino a distância em todos os níveis - seguem diretivas dos organismos internacionais, no sentido da privatização das políticas sociais, de favorecimento da expansão dos serviços privados, de diversificação e massificação do ensino e de reconfiguração das profissões (BOSCHETTI, 2008, p. 07).

Muitas das propostas e ações do governo Lula feriram a autonomia universitária: a) legalização das fundações privadas nas universidades, através da sua regulamentação (Decreto $\mathrm{n}$ - 5.205/2004; b) estímulo à ampliação das parcerias e convênios com as instituições privadas; c) parcerias público-privadas que permitem a destinação de verbas públicas para a iniciativa privada e desta para o setor público; d) Projeto de Lei de Inovação Tecnológica, que repassa a responsabilidade de produção de conhecimento para o setor privado; e) Programa Universidade para Todos - Prouni (MP no 213), que regulamenta a "compra" das vagas ociosas nas universidades particulares, destinando, dessa forma, verba pública para salvar os empresários desse setor; 
f) Projeto de Emenda Constitucional (PEC 217) da deputada Selma Schons (PT-PR), que prevê a cobrança de impostos a ex-alunos de universidades públicas; e g) Sistema Nacional de Avaliação do Ensino Superior Sinaes (Lei no 10.861 , de 14 de abril de 2004), que pouco difere do antigo "Provão", mantendo a utilização de critérios burocráticos e meritocráticos e a classificação dos cursos.

No período do governo Lula foi alimentada e mantida a ideia de que a educação é um serviço não exclusivo do Estado. Logo, investimentos públicos foram dirigidos às instituições privadas e investimentos privados foram sendo alocados em instituições públicas. Desse modo, cada vez mais esse movimento foi se fortalecendo e naturalizado, rompendo barreiras entre ambos os setores, balizados pela ótica neoliberal e ancorada em organismos internacionais como o Banco Mundial, entre outros.

Ações e estratégias são intensificadas, com vistas a alinhar as diretrizes internacionais e ampliar o vínculo com o mercado. A contrarreforma, entendida assim por alguns autores, expressa o objetivo de reordenamento da política de educação superior. De forma velada, o Estado tem afirmado que o caminho adotado é eficaz, Contudo, o discurso "ideológico de modernização das IESs", na prática, tem demonstrado uma lacuna muito grande da estrutura e da finalidade das universidades.

É importante que se diga que o Prouni, uma das propostas adotadas pelo governo Lula, significou a "salvação" para as universidades privadas, uma vez que se encontravam à beira da falência, tendo em vista $\mathrm{o}$ alto índice de inadimplência e o grande número de vagas ociosas existentes. Esse movimento de compra de vagas também significou uma forma de privatização da educação superior no Brasil.

O Ministério da Educação brasileiro estabelece as metas para o setor a cada dez anos em um documento chamado Plano Nacional de Educação (PNE). O PNE 2011-2020 deixa claro que o principal esforço do governo é melhorar a educação básica e que o ensino universitário é uma área que deve crescer com o auxílio público ao capital privado.

Pela análise do ensino superior (ES), a partir dos objetivos estabelecidos pelo PNE 2011-2020, a meta 12 aponta para a necessidade de elevar em $50 \%$ a taxa bruta de matrículas da população entre 18-24 anos no ES. Nesse caso, o documento afirma textualmente que, para alcançar tal objetivo, o aumento de matrículas será constituído principalmente nas instituições de ensino superior (IESs) privadas. Assim, o papel do Estado, afirma-se, seria aumentar programas como o Prouni (Programa Universidade para Todos) e o Fies (Fundo de Financiamento Estudantil), por mais que o documento não traga objetivamente o nome dos programas.
Na sequência da análise, a meta 15 do PNE alinha o desenvolvimento da educação básica (EB) à de educação superior, ao definir que até 2020 todos os professores da educação básica deverão ter formação universitária na área que lecionam. Para isso, o Fies deve ser ampliado e deve ser instituída uma taxa menor de juros $(1 \%$ no máximo) para aqueles que trabalhem na rede pública de ensino, além da ampliação das vagas do Prouni para professores da mesma rede. Conclui-se, através da análise do PNE 2011-2020, que o plano de privatização da educação superior, a partir da diminuição proporcional dos investimentos nas IESs públicas e da transferência de recursos para o setor privado, segue em pauta.

Diante disso, na sequência, é abordada uma das estratégias do governo federal, desde 2005 até o presente momento, no sentido de inserir segmentos populacionais até então excluídos do processo da educação superior, por meio do programa instituído como Prouni - Programa Universidade para Todos. São apresentadas diferentes perspectivas e posições para análise dessa política.

\section{PROUNI: DA ORIGEM À MATERIALIZAÇÃO DO PROGRAMA}

O Programa Universidade para Todos - Prouni - tem por finalidade conceder bolsas de estudos integrais e parciais em cursos de graduação sequenciais de formação específica, em instituições de ensino superior privadas. Em contrapartida, o governo federal isenta de tributos fiscais aquelas que aderirem ao programa. O Prouni foi criado pelo governo federal em 2004 e institucionalizado somente no ano seguinte, pela Lei no 11.096 , em 13 de janeiro de 2005.

Destinado a egressos do ensino médio da rede pública ou da rede particular na condição de bolsista integral, o programa atinge estudantes com renda familiar per capita de até um salário mínimo e meio para bolsistas integrais e de até três salários mínimos para bolsistas parciais. Os candidatos são selecionados pelas notas obtidas no Exame Nacional do Ensino Médio (Enem), reafirmando questões históricas ligadas à meritocracia no país, onde os mais aptos e qualificados ocupam os espaços, enquanto os desqualificados e desprovidos de condições para concorrer sofrem com a exclusão.

Cabe aqui ressaltar que esse programa fazia parte da proposta de reforma universitária do governo Lula e no governo Dilma continuou a se expandir, seguindo a lógica da privatização da educação superior. O processo de construção até a aprovação do projeto de lei não foi tranquilo como possa aparentar, pois muitas concessões foram realizadas no decorrer do caminho, atingindo diretamente as políticas das instituições de ensino superior, privadas e filantrópicas brasileiras. 


\begin{abstract}
A Reforma Universitária do governo Lula compreende, além do Prouni: quotas para alunos de rede pública (com subcotas para negros e indígenas) em universidades públicas federais; obrigatoriedade do Exame Nacional do Ensino Médio (Enem) para os seus concluintes; ampliação das universidades federais; criação de loteria federal para financiar a educação superior destinada ao levantamento de recursos para o Fies (Financiamento ao Estudante do Ensino Superior) e as bolsas-permanência para estudantes de baixa renda no ensino superior (CATANI; GILIOLI, 2005, p. 56).
\end{abstract}

A reforma universitária teria de cumprir seu papel de suprir a carência de vagas na rede de ensino superior, sem que aumentasse os gastos para a União. Diante disso, o Prouni seria uma alternativa plausível a ser adotada pelo governo. Seu objetivo também era atender ao Plano Nacional de Educação (PNE - Lei 10.172/2001), que tinha, dentre as metas, "prover, até o final da década, a oferta de educação superior para, pelo menos, $30 \%$ da faixa etária de 18 a 24 anos". Estudantes que concluíam o ensino médio e não ingressavam no ensino superior, apesar das vagas ociosas existentes na rede privada, muito em razão da situação socioeconômica de média e baixa renda.

Sendo assim, acredita-se que as IESs privadas e filantrópicas viram no Prouni uma excelente oportunidade de enfrentar o peso das vagas excessivas e uma estratégia de sobrevivência financeira dada a situação precária. Isso porque a realidade atual era de um grande número de inadimplências que incidiam diretamente sobre as finanças das instituições. A proposta inicial do MEC era que fosse uma medida provisória. Entretanto, decidiu-se encaminhar ao Congresso um Projeto de Lei $^{2}$. Diante disso, cabe aqui apontar alguns aspectos nas mudanças legais ocorridas:

- O PL previa apenas a concessão de bolsas de estudo integrais.

- Os critérios estabelecidos para selecionar os beneficiários foram as notas e o perfil socioeconômico do estudante no Enem (exceto para professores da rede pública). Aqueles estudantes que ingressassem via Prouni estariam dispensados do vestibular.

- O Prouni deu ênfase à inclusão de políticas afirmativas, garantindo a destinação de percentuais das bolsas aos autodeclarados negros e indígenas.

\footnotetext{
${ }^{2}$ Cabe aqui uma distinção entre Medida Provisória (MP) e Projeto de Lei. A primeira refere-se a um ato unipessoal da Presidência da República, que tem poder de lei, mas em razão de não passar pelo Poder Legislativo assim não se define. A MP tem caráter de urgência e relevância política, social e/ou econômica. Já o Projeto de Lei estabelece uma proposta normativa que, submetida ao legislativo, visa a produzir uma lei. Normalmente, um projeto de lei depende ainda da aprovação ou do veto do Poder Executivo.
}

- O vínculo das IESs ao Prouni se daria por meio do "termo de adesão", a ser assinado com o $\mathrm{MEC}$, vigente por 10 anos e renováveis por igual tempo. No entanto, "ficaria vedada a participação no programa de instituições com desempenho insuficiente no Sistema Nacional de Avaliação de Educação Superior (Sinaes), 'por dois anos consecutivos ou três intercalados, no período de

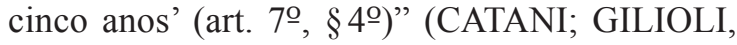
2005, p. 57).

- As instituições que aderissem ao Prouni teriam os benefícios de isenções fiscais: Imposto de Renda das Pessoas Jurídicas (IRPJ); Contribuição Social sobre o Lucro Líquido (CSLL); Contribuição Social para o Financiamento da Seguridade Social (Cofins); e Contribuição para o Programa de Integração Social (PIS). O que revela que uma gama de impostos deixa de ser recolhida e revertida em bolsas de estudos.

- Um critério criado pelo PL para as IESs foi de que somente aquelas que aderissem ao Prouni poderiam se credenciar ao Fies. Esse condicionante gerou muitos reveses, e já na MP foi alterado o texto, abrandando essa restrição e apenas ressaltando que aquelas IESs que aderissem ao Prouni teriam prioridade na distribuição dos recursos do Fies.

De acordo com Catani e Gilioli (2005), no momento em que a PL chegou ao Congresso Nacional, as associações de mantenedoras articuladas e organizadas apresentaram uma contraproposta ao governo, a fim de alterar algumas normas estabelecidas pelo Prouni. Instituições que foram representadas principalmente pela Associação Nacional das Universidades Particulares (Anup), Associação Brasileira de Mantenedoras de Ensino Superior (Abmes) e Sindicato das Entidades Mantenedoras de Estabelecimentos de Ensino Superior no Estado de São Paulo (Semesp). E grande parte das suas solicitações foram apresentadas via emendas de deputados e tão logo atendidas.

Essas reivindicações demonstram de forma clara as disputas políticas entre o Estado e as instituições, ora representadas pelo capital, e as correlações de força envolvidas. As políticas nacionais se assemelham cada vez mais no que se refere à orientação neoliberal de valorização do mercado e cortes nos gastos sociais. Esses cortes, sob a justificativa de reduzir a dívida pública, conduzem à desresponsabilização do Estado aos diretos sociais. Transferência de responsabilidades - nesse caso, a educação superior pública - dos governos para organizações não governamentais e privadas, descentralizando os serviços para outras regiões, que levou à perda de poder dos estados nacionais, deixando a dinâmica institucional à mercê das exigências internacionais. 
É necessário estar atento, pois o reflexo para o Serviço Social é visível. As políticas sociais são elaboradas sob essas tensões, e a dinâmica da profissão também é afetada, uma vez que as correlações de forças que redefinem a questão social podem transformar o Serviço Social em uma nova forma de legitimação do capitalismo neoliberal.

Isso aponta um campo de alta lucratividade para a educação: "O aumento do número de instituições de ensino superior/IES privadas reafirma a concepção da educação como um lucrativo negócio para as frações internacionais e locais da nova burguesia de serviços educacionais" (LIMA, 2013, p. 11). Há um explícito consenso em torno do projeto burguês de sociabilidade em tempos de neoliberalismo, no qual a educação é um serviço a ser vendido - a mercantilização da educação -, o contrário do seu entendimento de direito social.

Esse processo ocorre nos países centrais e periféricos. Nos primeiros, inicia-se com o Acordo de Bolonha, firmado entre os países europeus, que redefine os caminhos e os objetivos do ensino superior. Além de promover reformas nesse sistema, visando à formação de quadros superiores para que atendam às demandas e necessidades do mercado. E ainda transformando a educação em uma mercadoria com apoio e parceria firmada entre Estado e universidades privadas, por meio de sua expansão.

No caso dos países periféricos, como o Brasil, esse reordenamento no ensino superior foi alavancado nos governos de Fernando Henrique Cardoso e Luiz Inácio Lula da Silva, investindo na certificação em larga escala e na massificação da formação profissional como seus horizontes político-pedagógicos.

Reafirma-se mais uma vez o papel fundamental do Estado brasileiro na reestruturação da política de educação superior. É este que viabiliza juridicamente a política, autorizando e credenciando as IESs privadas, legalizando as IESs públicas no processo de privatização, e estimulando o produtivismo e o padrão mercantil na pesquisa e na produção de conhecimento. Conforme exposto por Kátia Lima (2005, p. 12), "as concepções de educação superior - reduzida à educação terciária - e de universidade - como instituição de ensino e/ou instituição subsumida à lógica mercantil - são compartilhadas por reitores das universidades e por parte dos docentes dessas IES".

Nesse sentido, o Prouni atende a uma necessidade premente brasileira, que é o ingresso da população brasileira no ensino superior, principalmente a grande parcela mais jovem e pobre, que historicamente está fora desse circuito. Isso se dá por meio da privatização e da mercantilização da educação superior, via aumento do número de IESs privadas e do financiamento público indireto para o setor privado. Essa política de expansão não pode ser apreendida de maneira ingênua, pois, apesar de o
Prouni ser um programa que priorize atender a segmentos da população, que anteriormente não participariam desse processo, ainda se configura como uma medida paliativa. Isso porque apresenta fragilidades desde o acesso até sua permanência. Sem contar que, embora seja um fundo público investido em âmbito privado, educação é dever do Estado e direito universal de todo cidadão, devendo este ser público e de qualidade.

Para Catani e Gilioli (2005, p. 58), após tantas reivindicações e emendas sofridas, o Prouni começou a se alterar e, assim, "na melhor das hipóteses, constitui-se em programa assistencialista que prioriza o acesso - e não a permanência - do estudante ao ensino superior". Esse ponto também foi levantado pelos representantes das mantenedoras, tendo em vista o critério da renda como esses estudantes iriam manter-se na universidade e garantir a conclusão do curso.

Uma das alternativas encontradas pelo governo foram as bolsas-permanência, entretanto estas são destinadas a estudantes com bolsa integral, matriculados em cursos presenciais com no mínimo seis semestres de duração, cuja carga horária média seja igual ou superior a seis horas diárias de aula. Tais regras excluem automaticamente mais da metade dos estudantes beneficiários do Prouni, pois são os cursos como Medicina, algumas Engenharias e poucos outros que exigem carga horária igual ou superior a seis horas diárias. Outro ponto importante é que boa parcela do público do Prouni é trabalhador e não dispõe de tal carga horária. Diante disso, o governo deixa em aberto essa questão e afirma que também é papel da universidade viabilizar a permanência do aluno.

Finalmente, após tantos debates e alterações ocorridas, o Congresso Nacional sanciona a Lei do Prouni no 11.096, em 13 de janeiro de 2005. O produto final traz em seu texto bolsas integrais e parciais, com a proporção de que a cada nove alunos pagantes o décimo deverá ser bolsista integral. No entanto, a fragilidade manteve-se ao tratar da permanência do aluno, pois fica sob a responsabilidade, sob o "cuidado" das IESs privadas manter o bolsista.

Nesse sentido, Catani e Gilioli (2005, p. 65) são assertivos ao parafrasear uma epígrafe da Lei Áurea quando referem: "Quebram-se algumas correntes que impediam o acesso à educação superior, mas não se oferece mais do que um arremedo de cidadania”.

Seria possível, nesse sentido, garantir o direito à educação superior dentro da lógica em que o Prouni foi concebido e vem sendo operado? O que faz o Prouni ser diferente das práticas anteriores existentes? Na verdade, não se constata muita diferença. O Prouni é uma política de governo que vem sendo executada pela esfera privada, replicando práticas já conhecidas na assistência social, em que a sociedade civil opera serviços que deveriam ser executados pelo público, reduzindo suas 
responsabilidades e encobrindo direitos. Isso resulta em práticas assistencialistas, burocratizantes e paliativas.

A partir dessa análise acerca da origem e natureza do programa, entende-se que a funcionalidade do Prouni está pautada na disponibilidade de vagas para estudantes em condições socioeconômicas fragilizadas, a baixos custos para a União.

O ano de 2012 foi o que mais registrou a concessão de bolsas Prouni, totalizando 284.622, sendo que, destas, 150.870 foram integrais e 133.752 parciais, segundo dados disponibilizados pelo MEC no Sisprouni, em 27-06-2012. E, do total de bolsas concedidas durante o ano de 2012, 64\% ficaram concentradas em apenas cinco estados, conforme demonstra a tabela abaixo.

Tabela 1. Dados Sisprouni

\begin{tabular}{lc}
\hline \multicolumn{1}{c}{ Estado } & $\mathbf{N}^{\mathbf{0}}$ de Bolsas \\
\hline São Paulo & 90.362 \\
Minas Gerais & 31.158 \\
Paraná & 27.956 \\
Rio Grande do Sul & 17.438 \\
Rio de Janeiro & 15.399 \\
Total & $\mathbf{1 8 2 . 3 1 3}$ \\
\hline
\end{tabular}

Fonte: MEC/Sisprouni, 27-06-2012.

No que se refere a sua funcionalidade para as instituições privadas, observa-se que é a forma de mantê-las "vivas", em virtude das inúmeras isenções fiscais, bem como da otimização das vagas anteriormente ociosas. Ao pensar que uma das diretrizes da educação é a formação para o trabalho, o Prouni cumpre um papel de fundamental relevância. Jovens e adultos que anteriormente não vislumbravam a possibilidade de acessar o ensino superior e se qualificar tecnicamente hoje já têm essa possibilidade. Logo, o mercado tem à disposição mais profissionais qualificados a ocupar os postos de trabalho.

\section{CONSIDERAÇõES FINAIS}

Cabe destacar que esses cinco estados da federação, onde as bolsas do Prouni mais se concentram, são, também, os mais desenvolvidos. Diante disso, cabe uma reflexão: se o intuito do programa é diminuir as desigualdades sociais e educacionais através da garantia do acesso à educação superior, esses investimentos não deveriam concentrar-se em estados menos desenvolvidos? E por que isso não ocorre? E, ainda, qual seria de fato a funcionalidade dessa política? Não se tem respostas definitivas para tais questões, embora se saiba que hoje a educação transformou-se em um grande negócio, do qual grandes empresários se apropriaram, lucrando muito com a oferta desse serviço.
Não obstante o Prouni ser um programa que tenha proporcionado o acesso à educação a muitos brasileiros, sua funcionalidade na prática está pautada em encobrir a ausência do Estado, no que diz respeito a investimentos na educação superior pública, bem como promover-se politicamente. Logo, pode-se dizer que esse programa não configura uma política de Estado, mas sim uma política de governo. E uma política de governo pode se desfazer a qualquer tempo.

É inegável que o governo tenha realizado maciços investimentos nesse setor e que na atual conjuntura econômica, política e social, sem a rede privada, não dê conta de atender às metas apontadas pela PNE 21120210 descritas no subitem anterior. Embora se preconize uma educação pública e de qualidade, os investimentos exigidos para efetivar tais ações são muito superiores aos destinados hoje ao Prouni. Mesmo assim, esse programa cumpre um importante papel na sociedade atual, que é proporcionar o acesso à educação a baixos custos, qualificando o máximo de pessoas para o mercado de trabalho.

\section{REFERÊNCIAS}

BOSCHETTI, Ivanete. Exame de proficiência: uma estratégia inócua. In: Revista Serviço Social e Sociedade, São Paulo, n. 94, p. 05-21, 2008.

BRASIL. Lei no 10.172/2001. Plano Nacional da Educação 2011-2020. Disponível em: <http://ne.mec.gov.br/images/ pdf/notas_tecnicas_pne_2011_2020.pdf>. Acesso em: 20-122013.

BRASIL. Lei no 11.096, de 13 de janeiro de 2005. Prouni.

BRASIL. Lei no 9.394, de 20 de dezembro de 1996. Estabelece as Diretrizes e Bases da Educação Nacional. Educação Legislação Federal. Comissão de Educação e Cultura. Brasília: Edições Câmara, 2009.

CATANI, Afrânio M. C.; GILIOLI, Renato de S. P. O Prouni na encruzilhada: entre a cidadania e a privatização. Linhas Críticas, Brasília, v. 11, n. 20, p. 55-68, jan.-jun. 2005.

FIGUEIREDO, Erika S. A. Reforma do Ensino Superior no Brasil: um olhar a partir da história. Revista da UFG, ano VII, n. 2, dez. 2005. Disponível em: <http://www.proec. ufg.br/revista_ufg/45anos/C-reforma.html>. Acesso em: 10 jul. 2012.

FREIGAT, Barbara. Escola, estado e sociedade. São Paulo: Moraes, 1980.

FREIGAT, Barbara. Escola, estado e sociedade. São Paulo: Moares, 1986.

KOWALSKI, Aline Vieiro. Os (des)caminhos da política de assistência estudantil e o desafio na garantia de direitos. Tese (Doutorado em Serviço Social) - Faculdade de Serviço Social, Pontifícia Universidade Católica do Rio Grande do Sul, Porto Alegre, 2012.

LIMA, Kátia. Contra-reforma na educação superior: de FHC a Lula. São Paulo: Xamã, 2007. 
LIMA, Kátia. Expansão da educação superior brasileira na primeira década do novo século. In: PEREIRA, Larissa D.; ALMEIDA, Ney L. T. (Org.). Serviço Social e Educação. 2. ed. Rio de Janeiro: Lumen Juris, 2013.

ONU-UNESCO - Organização das Nações Unidas para Educação, a Ciência e a Cultura. Fundo das Nações Unidas para a Infância. Programa das Nações Unidas para o Desenvolvimento. Banco Mundial. Relatório final: Declaração Mundial sobre Educação para Todos. Conferência Mundial de Educação para Todos, 1990. Brasília. Disponível em: <http://www.unesco.org.br/ publicacoes/copy_of_pdf/decjomtien>. Acesso em: 13 abr. 2012.
PIANA, Maria Cristina. A construção do perfil do assistente social no cenário educacional. São Paulo: Cultura Acadêmica, 2009.

PILETTI, Nelson. História da educação no Brasil. São Paulo: Ática, 2000.

ROMANELLI, Otaíza de Oliveira. História da educação no Brasil: 1930-1973. Petrópolis: Vozes, 1999.

Recebido em 17-09-2015.

Aprovado em 08-06-2016. 